\title{
Apoptosis and necrosis induced by novel realgar quantum dots in human endometrial cancer cells via endoplasmic reticulum stress signaling pathway
}

This article was published in the following Dove Press journal:

International Journal of Nanomedicine

3I August 2015

Number of times this article has been viewed

\author{
Huan Wang ${ }^{1-3}$ \\ Zhengyun $\mathrm{Liu}^{4}$ \\ Ying $\mathrm{Gou}^{3}$ \\ Yu Qin ${ }^{4}$ \\ Yaze $\mathrm{Xu}^{5}$ \\ Jie $\mathrm{Liu}^{4}$ \\ Jin-Zhu Wu ${ }^{6}$
}

'Research Center for Medicine and Biology, ${ }^{2}$ Guizhou Provincial College-based Key Lab for Tumor Prevention and Treatment with

Distinctive Medicines, ${ }^{3}$ Department of

Microbiology, ${ }^{4}$ Key Lab for Basic

Pharmacology of Ministry of Education,

${ }^{5}$ Pharmacy School, Zunyi Medical

College, Zunyi, ${ }^{6}$ Department of

Chemistry, School of Science,

Harbin Institute of Technology,

Harbin, People's Republic of China

Correspondence: Jin-Zhu Wu

Department of Chemistry, School of Science, Harbin Institute of Technology,

Number 92, West Da-Zhi Street, Harbin

I5000 I, People's Republic of China

Tel +86 I58 045I 5836

Fax +86 45। 864I 2I53

Email wujinzhu@hit.edu.cn

Huan Wang

Research Center for Medicine and

Biology, Zunyi Medical College, Dalian

Road Number 20I, Zunyi 563000,

People's Republic of China

Tel +86 85I 28609007

Fax +86 85I 28609676

Email wh@zmc.edu.cn

\begin{abstract}
Realgar $\left(\mathrm{A}_{\mathrm{S} 4} \mathrm{~S}_{4}\right)$ has been used in traditional medicines for malignancy, but the poor water solubility is still a major hindrance to its clinical use. Realgar quantum dots (RQDs) were therefore synthesized with improved water solubility and bioavailability. Human endometrial cancer JEC cells were exposed to various concentrations of RQDs to evaluate their anticancer effects and to explore mechanisms by the MTT assay, transmission electron microscopy (TEM), flow cytometry, real-time reverse transcriptase polymerase chain reaction (RT-PCR) and Western blot analysis. Results revealed that the highest photoluminescence quantum yield of the prepared RQDs was up to approximately $70 \%$, with the average size of $5.48 \mathrm{~nm}$. RQDs induced antiproliferative activity against JEC cells in a concentration-dependent manner. In light microscopy and TEM examinations, RQDs induced vacuolization and endoplasmic reticulum (ER) dilation in JEC cells in a concentration-dependent manner. ER stress by RQDs were further confirmed by increased expression of GADD153 and GRP78 at both mRNA and protein levels. ER stress further led to JEC cell apoptosis and necrosis, as evidenced by flow cytometry and mitochondrial membrane potential detection. Our findings demonstrated that the newly synthesized RQDs were effective against human endometrial cancer cells. The underlying mechanism appears to be, at least partly, due to ER stress leading to apoptotic cell death and necrosis.
\end{abstract}

Keywords: realgar, quantum dots, apoptosis, necrosis, endoplasmic reticulum stress, endometrial cancer cells

\section{Introduction}

Realgar $\left(\mathrm{A}_{\mathrm{S} 4} \mathrm{~S}_{4}\right)$ has been used in traditional medicines since ancient times. In ancient China, realgar (called Xiong-Huang) was applied in the treatment of several diseases including headache, vertigo, sore throat, mouth ulcers, tongue ulcers, etc. ${ }^{1,2}$ In recent years, the effects of realgar on the proliferation and apoptosis of human ovarian and cervical cancer cells, ${ }^{3}$ human chronic myelogenous leukemia K562 cells, ${ }^{4}$ and human promyelocytic leukemia HL-60 cells ${ }^{5}$ have been reported. However, poor water solubility and the resultant poor bioavailability greatly hamper the clinical applications of realgar. ${ }^{6}$ Realgar nanoparticles were thus produced in an attempt to overcome such a hindrance..$^{2,7}$

Compared with the crude realgar powders, the smaller realgar nanoparticles did improve the bioavailability, as manifested by the increased cytotoxicity toward tumor cells and increased urinary excretion of total arsenic in rats. ${ }^{8}$ In general, realgar nanoparticles were more effective than crude realgar in antitumor studies. ${ }^{1,9}$ Recently, we have developed realgar quantum dots (RQDs) of smaller sizes, namely $5.48 \mathrm{~nm} .{ }^{10}$ The cytotoxic effects of realgar nanoparticles and RQDs on human gynecological cell lines 
(C180-13S, OVCAR, OVCAR-3, HeLa) were comparable to those of arsenic trioxide, ${ }^{2,8,9}$ but less toxic against normal human lung fibroblast cells (MRC-5) and colonic fibroblast cells (CCD-18Co). ${ }^{9}$ Having recently found that RQDs are also effective against cervical U14 tumor growth in U14 tumorbearing mice, ${ }^{10}$ we speculate that RQDs may demonstrate better activity and bioavailability in gynecological cancer therapy.

In this study, we investigated the cytotoxicity of RQDs in the JEC cells, an endometrial cancer cell line, ${ }^{11}$ and found that RQDs-induced endoplasmic reticulum (ER) stress is important in its antitumor effects.

\section{Materials and methods}

\section{Instruments, chemicals, and cell line}

Ultravoilet-visible (UV-vis) absorption spectrum was recorded on a Shimadzu UV 2450PC spectrophotometer (Shimadzu Corp., Kyoto, Japan). Photoluminescence (PL) spectrum was monitored on a Perkin Elmer LS 55 luminescence spectrometer (PerkinElmer Inc., Waltham, MA, USA). High-resolution (HR) transmission electron microscopy (TEM) images were obtained with an FEI Tecnai G2F30 microscope (FEI, Hillsboro, OR, USA). The as-prepared realgar QDs were appropriately diluted with Milli-Q water before instrumental analysis.

\section{Methods}

\section{Synthesis of RQDs}

Approximately $2.0 \mathrm{~g}$ of arsenic sulfide chemical was dispersed into $50 \mathrm{~mL}$ of ethanolamine under Ar gas bubbling and ultrasonication at $100 \mathrm{~W}$ for 15 minutes. This was followed by centrifugation at $1,500 \mathrm{rpm}$ for 5 minutes to remove undissolved residue. The resulting supernatant was transferred to a $250 \mathrm{~mL}$ three-neck flask and heated to $80^{\circ} \mathrm{C}$ with constant stirring for 12 hours. Then, the saturated water solution of citric acid was added dropwise to the above hot synthetic solution till $\mathrm{pH} 8.0 \pm 0.2$, which was kept at $80^{\circ} \mathrm{C}$ for another 36 hours. No size sorting was applied to any sample used for characterization in this work.

\section{Determination of photoluminescence quantum yield} The PL quantum yield (PL QY) of the synthesized RQDs was estimated by using the comparative method proposed by Williams et $\mathrm{al}^{12}$ after slight modification as follows:

$$
Q_{X}=Q_{R} \cdot \frac{A_{R}}{A_{X}} \cdot \frac{F_{X}}{F_{R}} \cdot\left(\frac{n_{X}}{n_{R}}\right)^{2}
$$

where $Q$ is the PL QY, $A$ is the absorbance of the solution, $F$ is the corrected PL emission intensity, and $n$ is the average refractive index of the solution. Subscripts $R$ and $X$ refer to the standard selected and RQDs, respectively.

Rhodamine B (Sigma-Aldrich Co., St Louis, MO, USA) is used as the standard for the PL QY calculation. To minimize reabsorption effects, the absorbance values of the standard and RQDs were controlled to be less than 0.05 at the respective excitation wavelengths. We chose $365 \mathrm{~nm}$ as the excitation wavelength for RQDs and $550 \mathrm{~nm}$ for Rhodamine B.

\section{Characterization of RQDs}

UV-vis absorption spectrum was recorded on a Shimadzu UV 2450PC spectrophotometer (Shimadzu Corp.). PL spectrum was monitored on a Perkin Elmer LS 55 luminescence spectrometer (PerkinElmer Inc.). Upconversion fluorescence spectrum was recorded by a Tsunami ${ }^{\circledR}$ femtosecond Ti:sapphire oscillator (Spectra-Physics, Santa Clara, CA, USA). HRTEM images were observed with a FEI Tecnai G2F30 microscope (FEI). The as-prepared RQDs were appropriately diluted with Milli-Q water before instrumental analysis. Scanning electron microscopy (SEM) images were taken by a Hitachi S-4300 microscope (Hitachi Ltd., Tokyo, Japan). To prepare the samples for SEM imaging, dried precipitates obtained by adding formic acid into the solution of synthesized RQDs were firstly scattered onto carbon conductor tape followed by coating with gold.

\section{Cell culture}

JEC cells were cultivated in Dulbecco's Modified Eagle's Medium (Thermo Fisher Scientific, Waltham, MA, USA) (Hyclone) supplemented with $10 \%$ fetal calf serum $\left(\mathrm{Gibco}^{\circledR}=\right.$ product line of Thermo Fisher Scientific, Waltham, MA, USA) and cultured in a humidified atmosphere of $5 \% \mathrm{CO}_{2}$ at $37^{\circ} \mathrm{C}$.

\section{Determination of cell proliferation}

The sensitivity of JEC cells to RQDs was determined using the MTT colorimetric assay. In brief, $10 \mu \mathrm{L}$ MTT reagents was added into each well and incubated at $37^{\circ} \mathrm{C}$ for 4 hours. The supernatant was aspirated, and formazan crystals were dissolved in $100 \mu \mathrm{L}$ dimethyl sulfoxide (DMSO) at room temperature (RT) for 10 minutes with gentle agitation. Absorbance of each sample was measured at $570 \mathrm{~nm}$ using a Thermo Multiskan Spectrum microplate reader (Thermo Scientific, Cleveland, OH, USA).

\section{Transmission electron microscopy}

For TEM analysis, cell pellets were fixed overnight in 3.5\% glutaraldehyde (0.1 M, pH 7.4 in Sorensen's buffer) at $4^{\circ} \mathrm{C}$ and subsequently processed for TEM observation. The cells were observed and photographed under a transmission electron microscope (Hitachi-7650, Hitachi Ltd.). 
Annexin V/propidium iodide double staining for apoptosis

JEC cells were stained with both Annexin V-FITC (fluorescein isothiocyanate) and propidium iodide (PI) using the Annexin-V-FITC/PI staining kit (Zoman Biotechnology, Beijing, People's Republic of China) in accordance with the manufacturer's instructions. Briefly, the cells $\left(3 \times 10^{5}\right.$ cells $/$ well $)$ were seeded in six-well plates and cultured overnight, followed by treatment of RQDs. Thereafter, the cells were digested with $0.25 \%$ trypsin and washed twice with PBS. The cells were suspended in $500 \mu \mathrm{L}$ binding buffer, $5 \mu \mathrm{L}$ Annexin V-FITC was added, and the resulting mixture was carefully agitated. Then, $10 \mu \mathrm{L}$ PI was added to the mixture. Following incubation for 20 minutes at RT, the ratio of apoptosis was detected using a FACSCalibur and CellQuest software (Beckman Coulter, Brea, CA, USA).

Determination of mitochondrial membrane potential (JC-I staining) by fluorescence microscopy

JEC cells were incubated in a medium containing $500 \mu \mathrm{L}$ JC-1 dye (Molecular probes, Fanbo Biochemicals, Beijing,
People's Republic of China) for 20 minutes at $37^{\circ} \mathrm{C}$, and washed with $1 \times$ JC-1 buffer. Subsequently, the cells were excited at $488 \mathrm{~nm}$, and the fluorescence emission was recorded at $530 \mathrm{~nm}$ and $590 \mathrm{~nm}$, respectively. Images were captured using the Leica SP2 confocal microscope (Leica Microsystems, Wetzlar, Germany).

\section{mRNA extraction and real-time PCR}

Total RNA was extracted using TRIquick Reagent (Solarbio, Beijing, People's Republic of China), and reverse transcription was carried out with $\mathrm{M}-\mathrm{MuLV}$ reverse transcriptase (Takara) according to the manufacturer's protocol. For PCR amplification, the primer sequences for GADD153 and GRP78 (the target gene each) as well as $\beta$-actin (an internal control gene) are given in Figure 1. Real-time PCR was done using the CFX96 Touch Detection System (Bio-Rad Laboratories Inc., Hercules, CA, USA) according to the manufacturer's instructions. Finally, the comparative $C_{\mathrm{T}}\left(2^{-\Delta \Delta \mathrm{CT}}\right)$ method was used to determine the relative concentration of the amplified products.
A

\begin{tabular}{ll}
\hline Gene & Primer sequences $\left(\mathbf{5}^{\prime} \rightarrow \mathbf{3}^{\prime}\right)$ \\
\hline GRP78 & F: TAATGGAACGACAGGCACAC \\
& R: TGAGGGCAGGATTTCAAGAC \\
GADD153 & F: CCACTCTTGACCCTGCTTCT \\
& R: ACCACTCTGTTTCCGTTTCC \\
B-Actin & F: TGACGTGGACATCCGCAAAG \\
& R: CTGGAAGGTGGACAGCGAGG \\
\hline
\end{tabular}

C

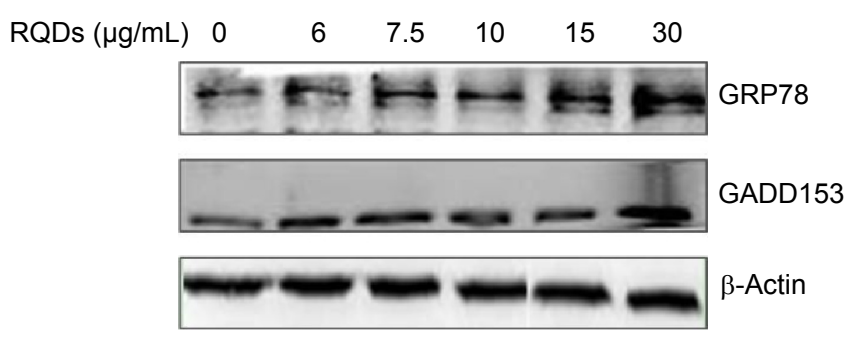

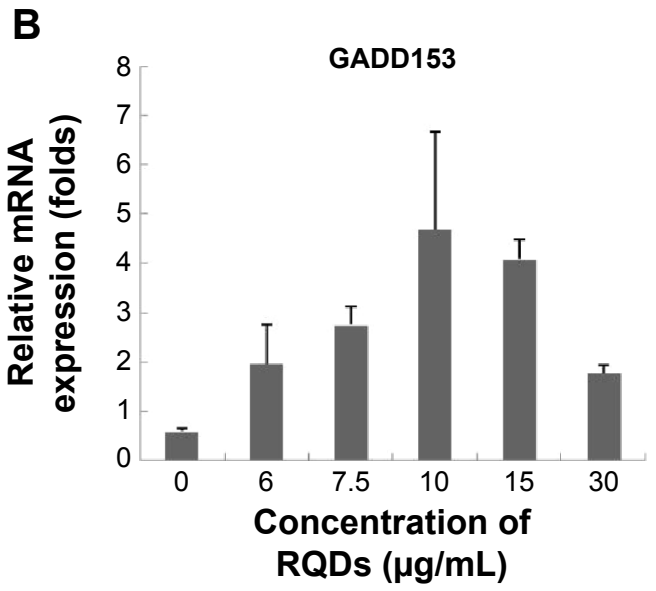

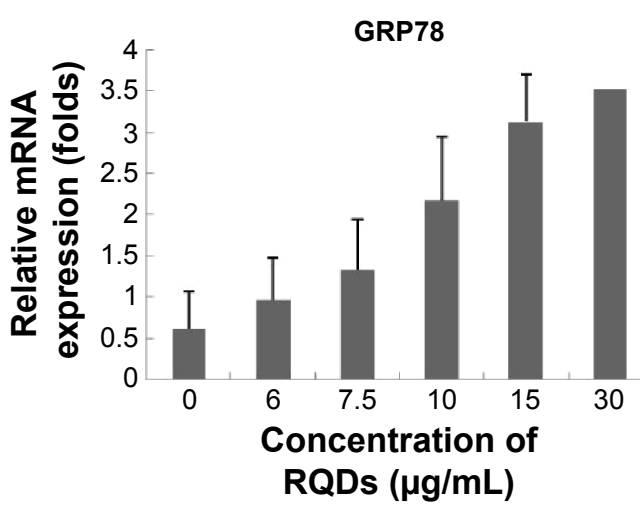

Figure I The expression of ER stress marker in JEC cells treated with different concentrations of RQDs.

Notes: (A) Primer sequences for real-time PCR. (B) The expression of GRP78 and GADDI53 mRNA. (C) The expression of GRP78 and GADDI53 protein. Abbreviations: RQDs, realgar quantum dots; ER, endoplasmic reticulum; PCR, polymerase chain reaction. 


\section{Western blot analysis}

Western blot analysis was performed according to the standard procedure. Briefly, cell lysates with equal amounts of proteins were loaded, separated by sodium dodecyl sulfate-polyacrylamide gel electrophoresis gels, and transferred onto the nitrocellulose membrane. The membrane was blocked with 5\% BSA (bovine serum albumin) for 1 hour and was incubated with specific primary antibodies (CST, CA, USA) at $4^{\circ} \mathrm{C}$ overnight, followed by appropriate horseradish peroxidase-conjugated secondary antibodies at RT for 1 hour. The bands were detected with the use of the enhanced chemiluminescence system.

\section{Statistical analysis}

All the data were analyzed using the SPSS 7.5-Windows Student's version software (SPSS Inc., Chicago, IL, USA).
For all the measurements, one-way ANOVA followed by Tukey's test was used to assess the statistical significance between groups. $P \leq 0.05$ was considered to be statistically significant.

\section{Results}

\section{Using ethanolamine and citric acid to synthesize RQDs}

The synthesis was directly monitored by observing the fluorescence of the aliquots taken from the synthetic system under a $365 \mathrm{~nm}$ UV lamp. The as-prepared RQDs were characterized using ethanolamine and citric acid. Figure 2A shows UV-vis absorption and PL emission spectra of RQDs colloidal solution after appropriate dilution, demonstrating typical band-edge emission of QDs. The representative PL
A

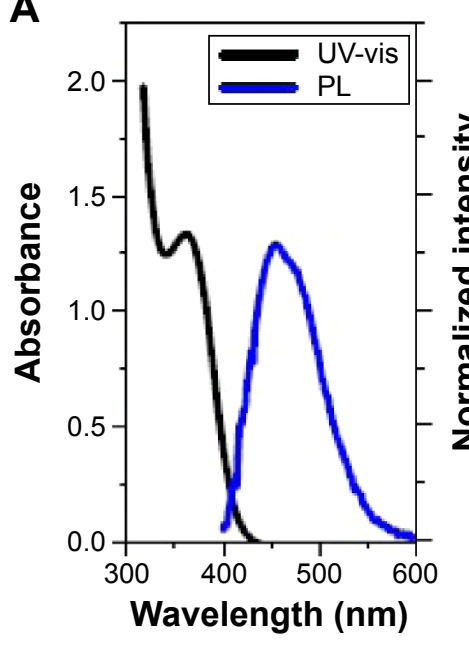

B

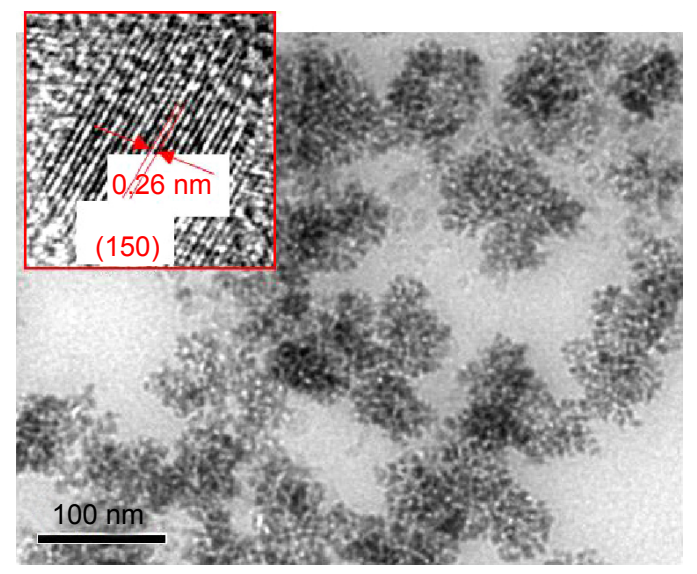

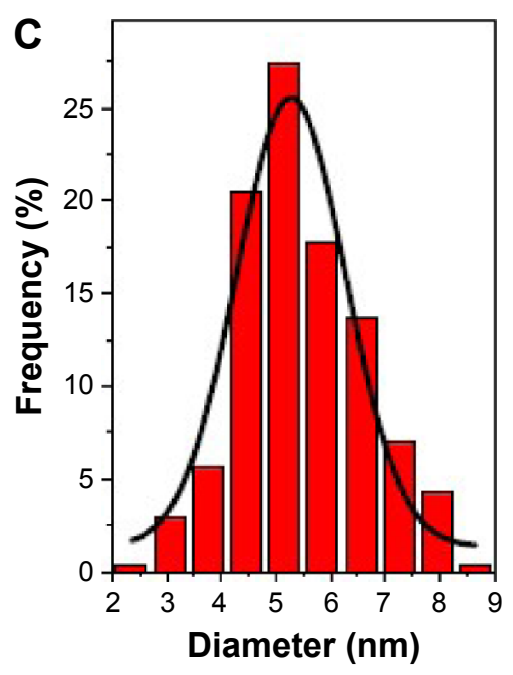

Figure 2 The characters of RQDs.

Notes: (A) UV-vis absorption and photoluminescence emission spectra of the as-prepared RQDs using ethanolamine and citric acid. Inset shows fluorescence photo under $365 \mathrm{~nm}$ UV light. (B) TEM and HRTEM images (inset) of the above RQDs, with the arrows emphasizing the $0.3 \mathrm{I} \mathrm{nm}$ distance of parallel between them. (C) Gives the corresponding size histogram and curve.

Abbreviations: UV-vis, ultravoilet-visible emission spectra; PL, photoluminescence emission spectra; RQDs, realgar quantum dots; TEM, transmission electron microscopy; HRTEM, high-resolution TEM. 
emission peak centered at $475 \mathrm{~nm}$ is well consistent with blue-cyan fluorescence observed under $365 \mathrm{~nm}$ UV light (Figure 2A). Single and symmetric PL emission peak shape suggests a narrow size distribution of the current RQDs (Figure 2A). Well-dispersed RQDs with an average size of $5.48 \pm 1.09 \mathrm{~nm}$ and a size distribution of $\sim 20 \%$ were observed in the TEM images and the corresponding size histogram (Figure 2B and C), well consistent with the corresponding optical spectra findings. Clearly resolved lattice fringes observed in a representative HRTEM image reveal the highly crystalline nature of the synthesized RQDs, in which an interplanar spacing of $\sim 0.26 \mathrm{~nm}$ matches the (150) facet of $\alpha-\mathrm{As}_{4} \mathrm{~S}_{4}$ crystal (Figure 2B inset).

\section{RQDs inhibit viability of human endometrial cancer} JEC cells and induce vacuolization and ER dilation JEC cells were treated with a range of concentrations of RQDs $(10,20,40,80,160 \mu \mathrm{g} / \mathrm{mL})$ for 48 hours. The percent cell viability compared with vehicle-treated controls was determined using the MTT assay. The cytotoxicity experiment (Figure 3) showed that RQDs reduced cell viability in a dosedependent manner, with the highest decrease (approximately $90 \%$ ) occurring with $80 \mu \mathrm{g} / \mathrm{mL}$.

When we examined the cellular morphologies following treatment of RQDs, widespread vacuolization of JEC cells was observed after 24 hours treatment (Figure 4A), and it was more serious with increasing concentration of RQDs. The gross morphological changes were further confirmed by electron microscopy. The treated cells displayed distension of the ER (Figure 4B).

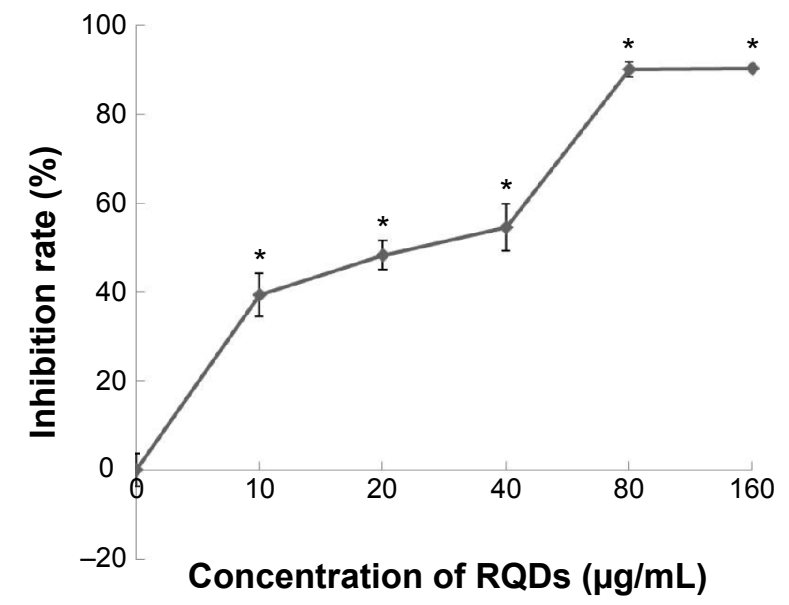

Figure 3 Concentration-dependent effects of RQDs on the cell viability of human endometrial cancer cells JEC.

Notes: After treatment of RQDs $(10,20,40,80$, and $160 \mu \mathrm{g} / \mathrm{mL})$ for 48 hours, the cell viability was analyzed using the MTT assay. The data are expressed as the mean \pm $S D$ of three experiments. ${ }^{*} P<0.05$ indicates statistically significant differences from the control group.

Abbreviations: RQDs, realgar quantum dots; SD, standard deviation.

\section{RQDs induce JEC cells apoptosis}

Annexin V-FITC/PI staining analysis demonstrated that treatment of RQDs resulted in a significant increase in apoptosis and necrosis in JEC cells (Figure 5A). In the $80 \mu \mathrm{g} / \mathrm{mL}$ group, the rate of apoptosis and necrosis was significantly increased to more than $80 \%$ after 24 hours treatment, higher than the other groups $(P<0.01)$ (Figure $5 \mathrm{~B})$. Measurement of mitochondrial membrane potential $(\Delta \psi \mathrm{m})$ is one of the methods used for studying the initiation of apoptosis. To explore the effects of RQDs on the mitochondrial membrane potential, JEC cells were cultured in RQDs at $15 \mu \mathrm{g} / \mathrm{mL}$ concentration for 24 hours and then processed for confocal microscopy analysis after being stained with fluorescent probe JC-1. After treatment with RQDs, the cells show increased green fluorescence (Figure 5C). This suggests that RQDs disrupt the mitochondrial membrane potential, resulting in the cytosolic accumulation of monomeric JC-1 as an indicator of apoptosis through the intrinsic pathway. Taken together, these data suggest that RQDs induce apoptosis and necrosis of JEC cells by activation of the mitochondrial pathway.

\section{Impact of RQDs on the ER stress signaling pathway in JEC cells}

To further assess ER stress involved in RQDs-induced apoptosis of JEC cells, the expression of the genes of ER stress, GRP78 (BIP) and GADD153 (CHOP), were detected by real-time reverse transcriptase polymerase chain reaction (RT-PCR) and Western blots. The results showed that RQDs induced a concentration-dependent GRP78 activation (Figure 1B and C). The mRNA expression level of GRP78 was increased 5.77 -fold in the $30 \mu \mathrm{g} / \mathrm{mL}$ group. The expression level of GADD153 was increased with the concentration of RQDs, the mRNA expression level of GADD153 was increased 7.98 -fold in the $10 \mu \mathrm{g} / \mathrm{mL}$ group, while it slightly decreased if the concentration of RQDs was more than $10 \mu \mathrm{g} / \mathrm{mL}$, probably due to cell death. The Western blot further confirmed the induction of GRP78 and GADD153 at the protein levels (Figure 1C). These results clearly indicate that RQDs induced ER stress in the JEC cells.

\section{Discussion}

Realgar $\left(\mathrm{As}_{4} \mathrm{~S}_{4}\right)$ presents promising anticancer effects. ${ }^{2}$ However, realgar is insoluble in water, resulting in poor bioavailability. RQDs are ideal to solve the problem.

To our knowledge, only one research group has addressed synthesis of realgar nanoparticles by a chemical method involving top-down and bottom-up procedures. ${ }^{9,13}$ They used ethylenediamine as a coordinating solvent to dissolve the 


\section{A}
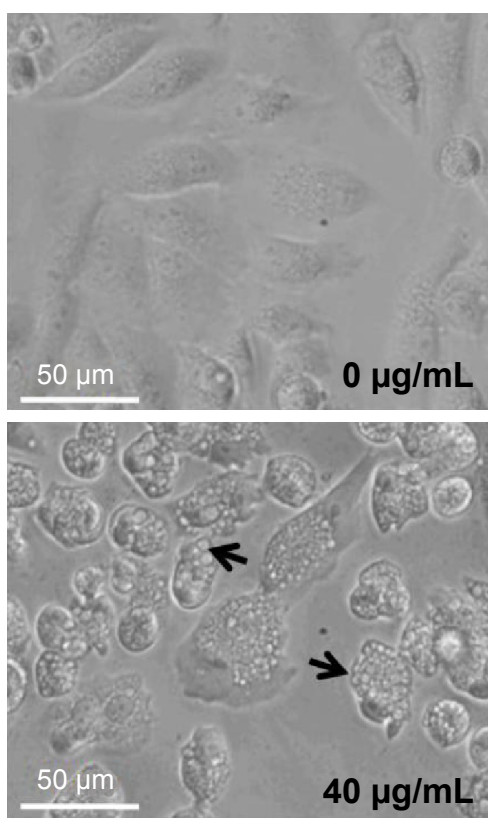
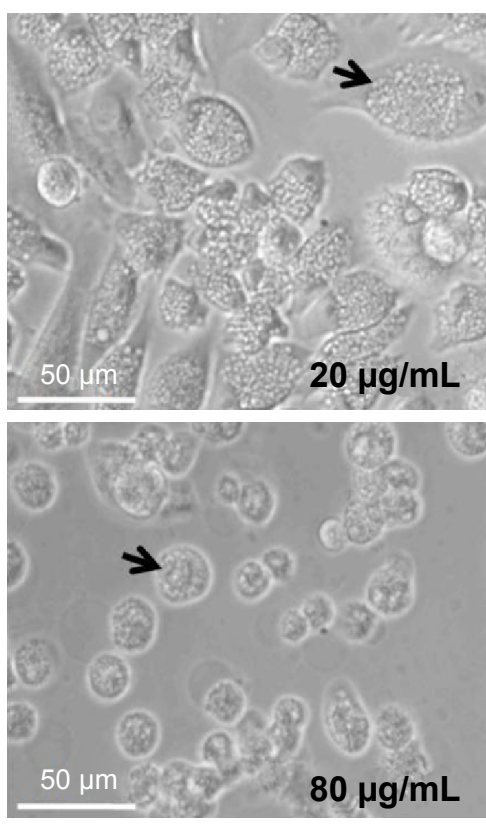

B
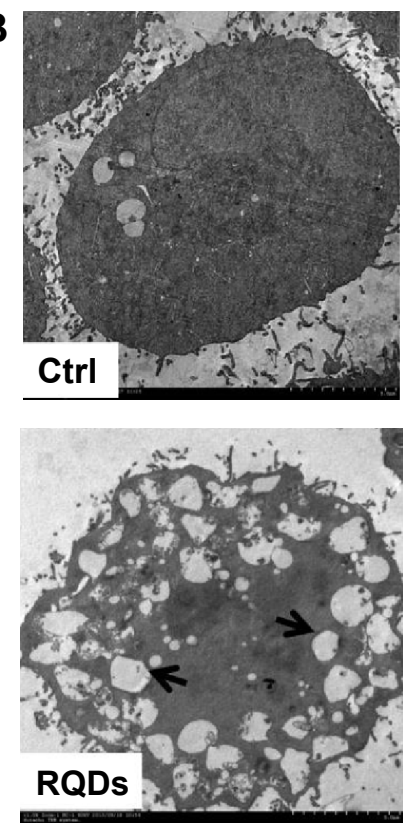

Figure 4 Morphological change of JEC cells treated with RQDs.

Notes: (A) Vacuolization induced by RQDs, with the arrows indicating the vacuolization and ER dilation. (B) Ultrastructural analysis of JEC cells by ultrathin section transmission electron microscopy.

Abbreviations: Ctrl, control; RQDs, realgar quantum dots.

coarse realgar powder in the first step and, in the following step, added acrylic acid as a protic agent to trigger the growth of RQDs. Encouraged by the previous reports, we chose less toxic ethanolamine and citric acid to synthesize RQDs via a similar method after modification. The highest PL QY of the as-prepared RQDs using ethanolamine and citric acid was up to the yield of $\sim 70 \%$, much better than the reported RQDs using ethylenediamine and acrylic acid with $15 \%$ PL QY. ${ }^{9}$ The RQDs are effective against human gynecological cell lines (C180-13S, OVCAR, OVCAR-3, HeLa) ${ }^{2,9}$ and against cervical tumor growth in mice without producing overt toxicity. ${ }^{10}$ In this study, we further demonstrated that RQDs are effective against human endometrial cancer (JEC) cells, suggesting that the smaller size of realgar in the form of RQD is promising for gynecological malignancy tumors.

Endometrial cancer is one of the most common gynecological malignancy tumors. Primary treatments consist of surgery, radiotherapy, and chemotherapy in most cases. ${ }^{14}$ Newly effective chemotherapeutic drugs are still greatly desired. ${ }^{15}$ The current study using endometrial cancer JEC cells clearly demonstrated that RQDs are effective in killing gynecological cancer cells, and that this effect is mediated through the ER stress signaling pathway.

Arsenic is known to induce stress responses. ${ }^{16}$ ER stress is initially shaped to reestablish ER homeostasis through the activation of an integrated intracellular signal transduction pathway termed as unfolded protein response (UPR). However, when ER stress is too severe or prolonged, the UPR turns from a prosurvival signal to a prodeath response, which is predominantly executed by mitochondrial apoptosis. ${ }^{17} \mathrm{ER}$ stress was suggested to be associated with arsenic effects in cells such as $\mathrm{CD}^{+}{ }^{+} \mathrm{T}$ lymphocytes ${ }^{18}$ chronic myeloid leukemia cell line $\mathrm{K} 562,{ }^{19}$ laryngeal squamous cell line Hep-2 cells, ${ }^{20}$ and in intact animals such as in mouse cerebrum ${ }^{21}$ and in liver. ${ }^{16}$ The current study clearly demonstrated that RQDs can also produce ER stress in JEC cells, as evidenced by widespread vacuolization with light microscopy and TEM. ER vacuolization is a characteristic of RQDs-induced morphological changes associated with the distension of ER. GRP78 and CHOP/GADD153 are typical ER stress protein genes. ${ }^{22,23}$ Our study revealed that RQDs-induced ER stress (as evidenced by morphology and increased GRP78 and GADD153) is an important mechanism for its anticancer effects.

Mitochondria represent key organelles for cell survival. JC-1 is a probe for the analysis of mitochondrial transmembrane potential changes occurring very early in apoptosis. ${ }^{24}$ The results of JC-1 staining observed in this study indicate that RQDs are capable of decreasing the mitochondrial $\Delta \psi \mathrm{m}$ and thereby inducing apoptosis in JEC cells.

Targeting apoptosis pathways is an important strategy in cancer therapy. As a programmed cell death, apoptosis occurs through two main pathways, extrinsic (Fas) and 
A
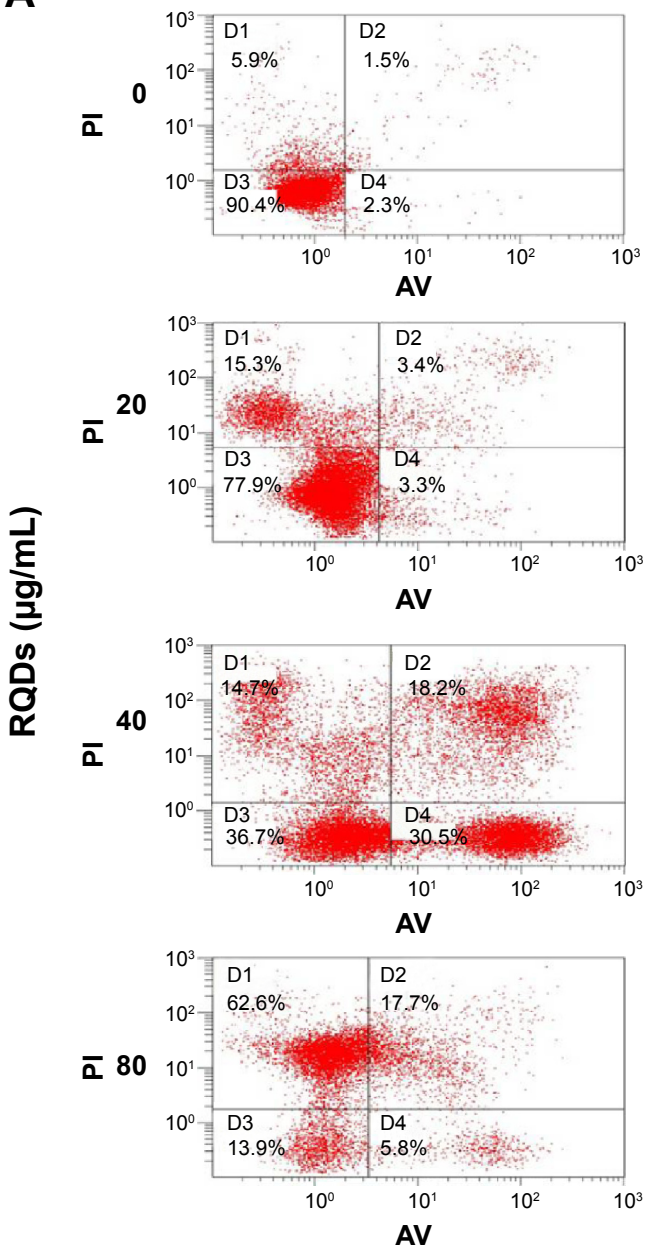

B
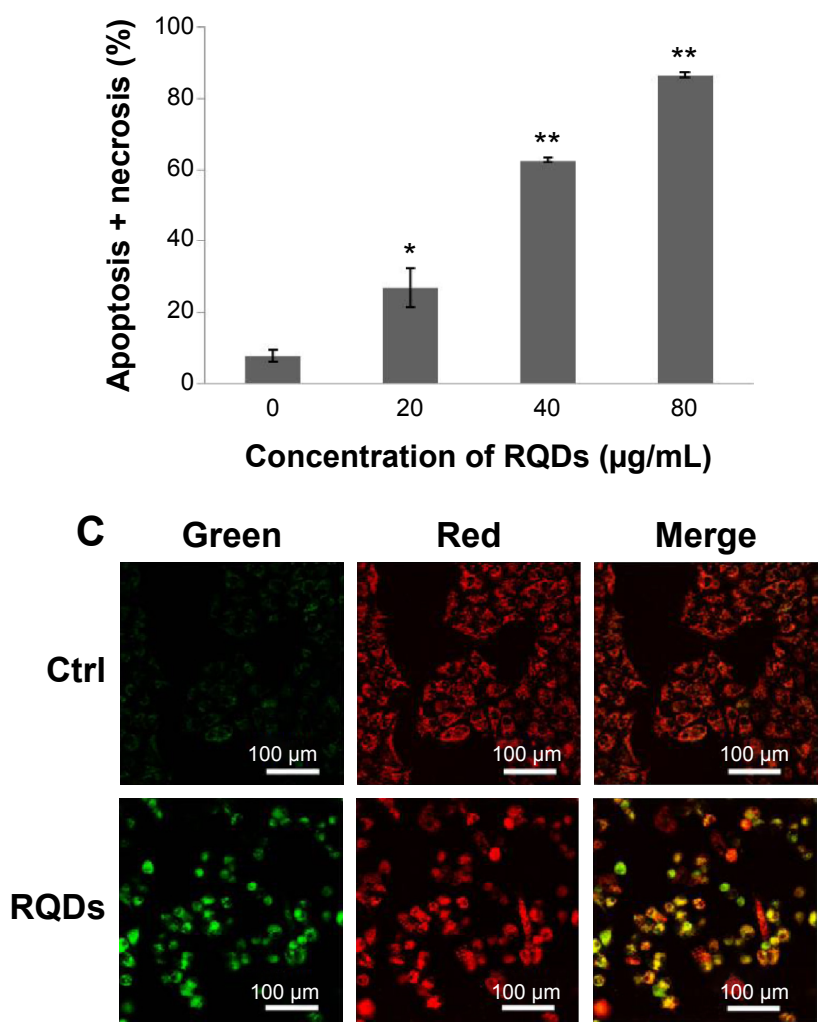

Figure 5 Induction of apoptosis in JEC cells following the RQDs treatment.

Notes: (A) Cells were treated with different concentrations of RQDs for 24 hours, and stained with Annexin V-FITC and PI, and then apoptotic cells were quantified by flow cytometry. In order to quantify the apoptotic rate, different subpopulations were distinguishable: DI, Annexin V-negative but PI-positive, ie, necrotic cells; D2, Annexin V/PI-double positive, ie, late apoptotic cells; D3, Annexin V/PI-double negative, ie, live cells; D4, Annexin V-positive but PI-negative, ie, early apoptotic cells. (B) The apoptotic rate was determined as the percentage of D2 + D4. ${ }^{28}(\mathbf{C})$ Mitochondrial membrane potential $(\Delta \Psi \mathrm{m})$ was analyzed using JC-I mitochondrial membrane dye. JEC cells were treated with DMSO (control) or RQDs $(15 \mu \mathrm{g} / \mathrm{mL})$ for 24 hour. The drug caused an increase in the green $(\mathrm{JC}-\mathrm{I}$ monomers) and decrease in the red fluorescence (JC-I aggregates), indicative of loss of $\Delta \Psi \mathrm{m}$. $* P<0.05$, $* * P<0.0$ I.

Abbreviations: RQDs, realgar quantum dots; PI, propidium iodide; DMSO, dimethyl sulfoxide; FITC, fluorescein isothiocyanate; ctrl, control; AV, annexin V.

intrinsic (mitochondria). Both pathways converge to final targets caspases and lead to cell death. ${ }^{25}$ In this study, we found that RQDs induced JEC cell apoptosis and necrosis, as evidenced by flow cytometry. The RQDs-induced apoptosis is clearly associated with mitochondrial membrane loss through ER stress, and it has been reported that when an ER stress is prolonged, it promotes the apoptotic process. ${ }^{26}$ Recently, the molecular mechanisms of realgar nanoparticlemediated melanoma cell killing were described, including autophagy and apoptosis, induction, as well as modulation of NF-kB, Akt, and MAP kinase signaling pathways. ${ }^{27}$ In our other work, we also found that RQDs are effective in induction of apoptosis protein Bax and suppression of antiapoptotic protein Bcl-2 in HepG2 cells.

\section{Conclusion}

In conclusion, the PL QY of RQD using ethanolamine and citric acid is up to $\sim 70 \%$, and the newly synthetic RQDs are a promising candidate anticancer agent against endometrial cancer cells by inducing apoptosis and necrosis. RQDsinduced ER stress and the loss of membrane potential appear to be important for RQDs to kill tumor cells.

\section{Acknowledgments}

This study was supported by the Science and Technology Foundation of Guizhou (CK-856, 2013-03) and the Key Lab Construction Project of the Educational Department of Guizhou (KY[2014]212), postdoctoral fellowship, Harbin Institute of Technology (HIT) (AUGA4110005410), the Fundamental 
Research Funds for the Central Universities (HIT. IBRSEM. 201331), and Program for Innovation Research of Science in Harbin Institute of Technology (PIRS of HIT 201411).

\section{Disclosure}

The authors report no conflicts of interest in this work.

\section{References}

1. An YL, Nie F, Wang ZY, Zhang DS. Preparation and characterization of realgar nanoparticles and their inhibitory effect on rat glioma cells. Int J Nanomedicine. 2011;6:3187-3194.

2. Wu JZ, Shao YB, Liu JL, Chen G, Ho PC. The medicinal use of realgar $\left(\mathrm{As}_{4} \mathrm{~S}_{4}\right)$ and its recent development as an anticancer agent. J Ethnopharmacol. 2011;135:595-602.

3. Du YH, Ho PC. Arsenic compounds induce cytotoxicity and apoptosis in cisplatin-sensitive and -resistant gynecological cancer cell lines. Cancer Chemother Pharmacol. 2001;47(6):481-490.

4. Li JE, Wu WL, Wang ZY, Sun GL. Apoptotic effect of $\mathrm{As}_{2} \mathrm{~S}_{2}$ on K562 cells and its mechanism. Acta Pharmacol Sin. 2002;23(11):991-996.

5. Ye HQ, Gan L, Yang XL, Xu HB. Membrane-associated cytotoxicity induced by realgar in promyelocytic leukemia HL-60 cells. J Ethnopharmacol. 2006;103(3):366-371.

6. Zhao W, Lu X, Yuan Y, et al. Effect of size and processing method on the cytotoxicity of realgar nanoparticles in cancer cell lines. Int $J$ Nanomedicine. 2011;6:1569-1577.

7. Tian Y, Wang X, Xi R, et al. Enhanced antitumor activity of realgar mediated by milling it to nanosize. Int J Nanomedicine. 2014;9: 745-757.

8. Wu JZ, Ho PC. Evaluation of the in vitro activity and in vivo bioavailability of realgar nanoparticles prepared by cryo-grinding. Eur J Pharm Sci. 2006;29(1):35-44.

9. Wang J, Lin M, Zhang T, et al. Arsenic(II) sulfide quantum dots prepared by a wet process from its bulk. J Am Chem Soc. 2008;130(35): 11596-11597.

10. Qin Y, Jin F, Jin H, Wu JZ, Liu J. Anti-tumor effects of realgar quantum dots and Liu-Shen-Wan in tumor-bearing mice. Chin J New Drug Clin Rem. In press.

11. Wu ZM, Liu ZL, Li WC. Establishment of the cell line JEC-9 of a human endometrial adenocarcinoma. Acta Acad Med Zunyi. 1991;14(1):44-47. Chinese.

12. Williams ATR, Winfield SA, Miller JN. Relative fluorescence quantum yields using a computer-controlled luminescence spectrometer. Analyst. 1983;108:1067-1071

13. Wang JZ, Loh KP, Wang Z, et al. Fluorescent nanogel of arsenic sulfide nanoclusters. Angew Chem Int Ed. 2009;48(34):6282-6285.
14. Galaal K, AI Moundhri M, Bryant A, Lopes AD, Lawrie TA. Adjuvant chemotherapy for advanced endometrial cancer. Cochrane Database Syst Rev. 2014;5:CD010681.

15. Wright JD, Barrena Medel NI, Sehouli J, Fujiwara K, Herzog TJ. Contemporary management of endometrial cancer. Lancet. 2012; 379(9823):1352-1360.

16. Liu J, Kadiiska MB, Liu Y, Lu T, Qu W, Waalkes MP. Stress-related gene expression in mice treated with inorganic arsenicals. Toxicol Sci. 2001;61(2):314-320.

17. Verfaillie T, Garg AD, Agostinis P. Targeting ER stress induced apoptosis and inflammation in cancer. Cancer Lett. 2013;332(2):249-264.

18. Li K, Zhang L, Xiang X, et al. Arsenic trioxide alleviates airway hyperresponsiveness and promotes apoptosis of CD4+ T lymphocytes: evidence for involvement of the ER stress-CHOP pathway. Ir Med Sci. 2013;182(4):573-583.

19. Du Y, Wang K, Fang H, et al. Coordination of intrinsic, extrinsic, and endoplasmic reticulum-mediated apoptosis by imatinib mesylate combined with arsenic trioxide in chronic myeloid leukemia. Blood. 2006;107(4):1582-1590.

20. Yang X, An L, Li X. Arsenic trioxide induced endoplasmic reticulum stress in laryngeal squamous cell line Hep-2 cells. Auris Nasus Larynx. 2014;41(1):81-83.

21. Yen CC, Ho TJ, Wu CC, et al. Inorganic arsenic causes cell apoptosis in mouse cerebrum through an oxidative stress-regulated signaling pathway. Arch Toxicol. 2011;85(6):565-575.

22. Lakshmanan AP, Thandavarayan RA, Palaniyandi SS, et al. Modulation of AT-1R/ CHOP-JNK-Capase12 pathway by olmesartan treatment attenuates ER stress-induced renal apoptosis in streptozotocin-induced diabetic mice. Eur J Pharm Sci. 2011;44(5):627-634.

23. Wu T, Dong Z, Geng J, et al. Valsartan protects against ER stress-induced myocardial apoptosis via $\mathrm{CHOP} /$ Puma signaling pathway in streptozotocininduced diabetic rats. Eur J Pharm Sci. 2011;42:496-502.

24. Ansil PN, Wills PJ, Varun R, Latha MS. Cytotoxic and apoptotic activitiesxs of Amorphophallus campanulatus (Roxb.) B1. tuber extracts against human colon carcinoma cell line HCT-15. Saudi J Biol Sci. 2014;21(6): 524-531.

25. Ghobrial IM, Witzig TE, Adjei AA. Targeting apoptosis pathways in cancer therapy. CA Cancer J Clin. 2005;55(3):178-194.

26. Chen L, Xu S, Wen X, Xu Y, Chen J, Teng J. Cab45S inhibits the ER stress-induced IRE1-JNK pathway and apoptosis via GRP78/BiP. Cell Death Dis. 2014;5:e1219.

27. Pastorek M, Gronesova P, Cholujova D, et al. Realgar $\left(\mathrm{As}_{4} \mathrm{~S}_{4}\right)$ nanoparticles and arsenic trioxide $\left(\mathrm{As}_{2} \mathrm{O}_{3}\right)$ induced autophagy and apoptosis in human melanoma cells in vitro. Neoplasma. 2014;61(6):700-709.

28. Liu X, Gao R, Chen X, et al. Possible roles of mmu-miR-141 in the endometrium of mice in early pregnancy following embryo implantation. PLoS One. 2013;8(6):e67382.
International Journal of Nanomedicine

\section{Publish your work in this journal}

The International Journal of Nanomedicine is an international, peerreviewed journal focusing on the application of nanotechnology in diagnostics, therapeutics, and drug delivery systems throughout the biomedical field. This journal is indexed on PubMed Central, MedLine, CAS, SciSearch ${ }^{\circledR}$, Current Contents ${ }^{\circledR} /$ Clinical Medicine,
Dovepress

Journal Citation Reports/Science Edition, EMBase, Scopus and the Elsevier Bibliographic databases. The manuscript management system is completely online and includes a very quick and fair peer-review system, which is all easy to use. Visit http://www.dovepress.com/ testimonials.php to read real quotes from published authors. 